\title{
GESTÃO DE PESSOAS NA PERCEPÇÃO DO PROPRIETÁRIO: ESTUDO DE CASO DE UMA PEQUENA EMPRESA DE EMBALAGENS
}

\section{PEOPLE MANAGEMENT IN THE OWNER'S PERCEPTION: A CASE STUDY OF A SMALL PACKAGING COMPANY}

\author{
Djair Picchiai ${ }^{1}$ \\ Doutorado em Administração de Empresas \\ Professor da EAESP-FGV \\ Fundação Getúlio Vargas \\ djair.picchiai@fgv.br \\ Bruna Thomaz Ventura \\ Graduada em Administração de empresas \\ Especialista em Inovação de Serviço \\ Fundação Getúlio Vargas \\ brunatventura@gmail.com
}

Recebido: 26/08/2016 - Aprovado: 10/11/2016 - Publicado: 10/12/2016 Processo de Avaliação: Double Blind Review

\section{RESUMO}

Este artigo procura analisar a gestão de pessoas e a percepção do gestor/proprietário quanto a esta função gerencial para a empresa Panther Embalagens Ltda., do setor industrial. O estudo consistiu em entrevista com o gestor/proprietário, no qual se analisaram os aspectos estratégicos estabelecidos sobre gestão de pessoas e a percepção deste sobre os mesmos. Além disso, mediu-se a percepção do clima organizacional pelos funcionários da fábrica por meio de aplicação de questionário validado. Utilizou-se também as observações e percepções dos autores ao longo do estudo de campo realizado e do convívio com as pessoas da empresa, bem como o acesso a materiais existentes na empresa relativos ao Departamento de Recursos Humanos. Constata-se a necessidade de descentralização das atividades e o poder de decisão de gestão de pessoas cuja centralização é comum a pequenas empresas. Verifica-se que os funcionários desejam mais autonomia e participação, de acordo com a pesquisa de clima organizacional.

\footnotetext{
1 Autor para correspondência: Fundação Getúlio Vargas, Av 9 de Julho, 2029, Bela Vista, São Paulo - SP, Brasil - CEP 01313-902.
} 
Palavras-chave: Pequena empresa; Liderança; Clima organizacional; Estratégia.

\begin{abstract}
This article aims to analyze the people management in an industry called Panther Embalagens Ltda., besides the perception of the manager/owner about the topic. The study consisted in a survey with the manager/owner, where was evaluated the strategic aspects defined about people management and his perception. Furthermore, the organizational climate was measured through a survey applied to the company employees.

Also, the perceptions and observations from the authors, made during the fieldwork and while in touch with the employees, was considered, as well as the information available in the company about Human Resources. The study identified the necessity to decentralize the decision-making power about people management, what is common in small companies. Also was possible to verify that the employees wish more autonomy and participation, according to the organizational climate survey.
\end{abstract}

Key-words: Small business; Leadership; Organizational climate. Strategy.

\title{
INTRODUÇÃO
}

Parte fundamental do sucesso de uma empresa está na gestão de pessoas (FLEURY, 2002; LACOMBE, 2005; HANASHIRO, 2006). Muito mais do que uma área de departamento pessoal, onde apenas os tradicionais processos eram executados, tais como recrutamento e seleção, avaliação, remuneração, benefícios, treinamentos, dentre outros, a área de gestão de pessoas é extremamente estratégica para uma empresa (FLEURY, 2002; LACOMBE, 2005; HANASHIRO, 2006), pois são nos módulos estratégicos em que as características individuais do profissional são consideradas, e principalmente porque, afinal, é sabido que tudo é realizado por meio das pessoas. (ARAÚJO e GARCIA, 2009)

O problema de pesquisa estudado é definido em função das respostas às seguintes perguntas: Como o gestor percebe a importância dos principais instrumentos da área de gestão de pessoas? Qual a percepção do gestor quanto à gestão estratégica de pessoas, bem 
como do clima organizacional da empresa? Qual o clima organizacional da empresa sentido por seus funcionários?

O escopo do trabalho deu-se por meio da análise da empresa por meio da realização de entrevista com o gestor e aplicação de pesquisa de clima organizacional junto aos funcionários, buscando identificar as diferentes percepções das duas partes. Quanto à gestão de pessoas, utilizam-se documentos existentes na empresa, bem como a imersão dos autores no dia-a-dia da Panther Embalagens Ltda., visando identificar aspectos relevantes para o estudo.

Como objetivo geral deste trabalho tem-se a descrição e análise das estratégias de gestão de pessoas da empresa Panther Embalagens Ltda., visando realizar um diagnóstico da situação e identificar pontos críticos de desempenho da empresa. Como objetivos específicos, destaca-se a análise do tema sobre três prismas principais, que são: os processos de gestão de pessoas, a estratégia de pessoas e o clima organizacional. Deste modo, busca-se uma visão holística sobre a área em questão. (BURKHARD E MOGGI , 1996)

As empresas, principalmente as de pequeno porte, não têm acesso a ferramentas eficazes de gestão, seja por um falta de estrutura ou por falta de know-how. Desta maneira, este trabalho visa, por meio de uma análise do ambiente de uma pequena empresa, com o apoio das teorias e pesquisa de campo, verificar a percepção do gestor/proprietário sobre a área de gestão de pessoas das pequenas empresas (PEs) e suas limitações conceituais e/ou práticas.

\section{REFERENCIAL TEÓRICO}

Desenvolve-se este estudo a partir de três pilares principais: processos da área de gestão de pessoas, estratégia de pessoas e o clima organizacional. Os três fatores objetos de estudo foram definidos a partir de um estudo dos autores da área. (FLEURY, 2002; HANASHIRO, 2008; LACOMBE, 2005; ARAÚJO, 2009; GARCIA, 2009)

Não há apenas um critério universal para definição da micro e pequena empresa (MPE) (LEONI, 1991 e 1999). Há diversos indicativos que podem caracterizar cada uma delas, mas estes não podem ser considerados definitivos para todos os tipos de contexto. Um dos aspectos mais importantes que levam a definição de tais critérios baseia-se, não apenas por razões fiscais, mas também para estabelecer diferentes tipos de benefícios oferecidos pelos governos. (LIMA, 2001) 
No artigo, consideram-se as classificações mais tradicionais e também mais utilizadas no Brasil - sendo elas a do SEBRAE (Serviço Brasileiro de Apoio à Micro e Pequena Empresa) e do BNDES (Banco Nacional de Desenvolvimento Econômico e Social).

Pode-se afirmar que a empresa objeto de estudo do trabalho em questão é considerada pequena empresa por meio dos dois critérios, uma vez que, está no segmento da Indústria, possui 38 funcionários e tem um faturamento anual entre o intervalo determinado pelo BNDES, segundo depoimento do próprio gestor/proprietário.

O primeiro passo para realizar o planejamento de recursos humanos foi realizar um diagnóstico do cenário da organização. Um instrumento para dar início a esse diagnóstico é a análise SWOT (Strengths, Weaknesses, Opportunities e Threats), desenvolvida na Universidade de Stanford, por meio dela se identificam os pontos fortes, pontos fracos, ameaças e fraquezas da empresa. Após a identificação da real situação da mesma, é importante definir um cenário no qual os gestores desejam que ela esteja dentro dos próximos anos a fim de nortear os próximos passos. (ULRICH, 1990)

Tendo delineado o cenário, é necessário definir as estratégias que viabilizem a sua materialização, traçando o planejamento estratégico. (OLIVEIRA, 2013; PICCHIAI, 2012) Este planejamento tem natureza indicativa, cujo objetivo é mostrar o que deve ser feito. Posteriormente, este deverá ser desdobrado para criação do planejamento operacional que, por sua vez, tem como função principal indicar como realizar tais atividades para se conquistar as estratégias definidas. $\mathrm{O}$ foco deste planejamento é a eficiência, o que exige que este seja extremamente detalhado com atividades a serem realizadas e cronogramas semanais, mensais ou trimestrais, para todas as áreas. (OLIVEIRA, 2013; PICCHIAI, 2012)

Tendo o planejamento estratégico da empresa definido, é possível estruturar e criar o planejamento dos recursos humanos necessários, sendo estes elementos cruciais para que toda estratégia e atividades definidas sejam executadas e os resultados alcançados. É fundamental que o planejamento de Recursos Humanos (RH) seja coerente e consistente com seu planejamento estratégico. A elaboração destes segundo a literatura (OLIVEIRA, 2013), é conjunta.

Um sistema de avaliação formal de modo a minimizar erros e subjetividades é necessário (LACOMBE, 2005). Os objetivos principais dessas avaliações são:

- Melhorar o desempenho da pessoa no cargo atual; 
- Fornecer informações para administração sobre o potencial do funcionário e suas qualificações;

- Indicar a possibilidade de promoções, treinamentos, demissões e o rumo do funcionário na empresa.

Para a aplicação de avaliação é necessário definir a finalidade da mesma, ou seja, priorizar um objetivo (melhorar o desempenho dos funcionários, identificar quais treinamentos são necessários para equipe, etc.). Tendo isto definido, é importante que todos os envolvidos sejam comunicados sobre o objetivo da avaliação que será realizada. (BERGAMINI, 1988)

Durante o processo de avaliação pede-se para que o funcionário realize uma autoavaliação para que ele tenha tempo de refletir sobre sua postura e seu trabalho de modo geral. Normalmente, as pessoas tendem a se auto valorizar, por isso é fundamental a avaliação também do seu superior imediato, e que este lhe passe um feedback sobre a avaliação. Por se tratar de um assunto delicado, é crucial que o superior tome alguns cuidados e elabore um roteiro de conversa de modo a passar o conteúdo necessário para o funcionário, sem que este leve para o lado pessoal. O superior deve-se limitar a falar dos resultados alcançados do trabalho, de preferência contrastando e comparando com a meta estabelecida e não abordar aspectos pessoais. Para que seja mais eficiente, busca-se começar falando dos pontos positivos da pessoa para que ela fique mais aberta a ouvir o que seu superior tem a dizer e também para que seja uma conversa informal, porém reservada apenas aos dois envolvidos, para que não seja criada nenhuma situação constrangedora para o funcionário e para que este possa se sentir mais à vontade. Os micro e pequeno empresários fazem isto intuitivamente, dada a contribuição de suas experiências e seus conhecimentos dos processos produtivos. O cognitivo destes é desenvolvido pela aprendizagem por meio do cotidiano. Os desafios, os problemas e as alternativas adotadas acabam sendo um processo de aprendizagem.

O recrutamento "é o processo de identificação e atração de um grupo de candidatos, entre os quais serão escolhidos alguns para posteriormente serem contratados para o emprego" (MILKOVICH e BOUDREAU, 2000; HANASHIRO, 2008; LACOMBE, 2005). Feito o recrutamento, inicia-se o processo de seleção, ou seja, selecionar o candidato que melhor se adequa às necessidades da empresa. A seleção considera o candidato não apenas para o cargo em questão, mas também, seu potencial de crescimento, por isso é necessário selecionar pessoas que tenham valores alinhados com os da MPEs, para que estes se adaptem 
melhor à sua cultura. É necessário avaliar não apenas o conhecimento técnico, mas também a personalidade do candidato, principalmente para vagas que exijam um maior contato com clientes. Devem ser priorizados candidatos que tenham habilidades e comportamentos que sejam difíceis de serem adquiridos por meio de treinamento, e que estejam de acordo com as reais necessidades da empresa. (LACOMBE, 2005)

Para o recrutamento externo, há diversas etapas para a seleção dos candidatos. As principais vantagens deste processo é a renovação de pessoas da organização; ausência de conflitos de relacionamento, pelo fato de não terem vínculo com pessoas da empresa; e a manutenção da racionalidade do processo (ARAUJO; GARCIA, 2009). Em contrapartida, é um processo mais lento, devido às várias etapas exigidas para conhecer os candidatos; alto investimento; uma possível desmotivação dos funcionários por acharem que seus esforços não estão sendo considerados; e a insegurança de contratar uma pessoa em que você só conhecerá, de fato, com o tempo e com o trabalho no dia-a-dia. Constitui-se num processo longo e caro para as pequenas empresas.

No plano misto, é possível fazer o recrutamento e seleção internamente e externamente. Pode-se iniciar com o primeiro e não havendo candidatos que se adequem, partir para o segundo, e vice-versa. Também é possível iniciar os dois, concomitantemente, sendo selecionada a pessoa que demonstrar o melhor talento e adequação à posição em aberto. O importante desta forma de recrutamento é tirar proveito dos principais pontos positivos de cada um dos métodos explicados anteriormente.

É importante ressaltar que cada segmento de mercado e empresa tem suas características e realidades próprias, havendo a possibilidade e necessidade de adaptação de tais técnicas para uma melhor adequação de efetividade do processo. Portanto, é muito importante que os gestores das MPEs tenham grande conhecimento do mercado e, sobretudo, de sua empresa e limitações, para poder traçar a melhor estratégia de recrutamento e seleção de seus funcionários.

A remuneração do fator trabalho, além de ser exigida legalmente, é um importante fator estratégico nas empresas por ser um instrumento indispensável para atrair e reter bons profissionais.

Cabe aos gestores identificar quais métodos lhe proporcionarão criar uma remuneração adequada a todos os seus funcionários, garantindo uma coerência interna entre os salários e benefícios de cada um, bem como uma coerência externa com o valor praticado pelo mercado. 
A remuneração inadequada pode acarretar a perda de motivação e, consequentemente, produtividade dos funcionários, e até mesmo a perda dos melhores profissionais para outras empresas, impactando negativamente em seus resultados.

Quando o benefício for obrigatório por lei, este é considerado encargo social. Dentro desta classificação estão incluídos: férias remuneradas, décimo terceiro salário, abono de férias, salário-maternidade, salário-família, seguro de acidentes de trabalho, salário-educação, horas extras, dentre outros. (LACOMBE, 2005)

Caso os benefícios não sejam obrigatórios, eles são concedidos por opção da empresa, por um acordo sindical ou apenas por uma questão estratégica. Neste caso, estão incluídas as gratificações como licença remunerada em caso de doença, seguro-saúde e/ou assistência médico-hospitalar e odontológica, ambulatório na empresa, refeições subsidiadas, estacionamento, creches para filhos, locais esportivos ou de lazer para serem utilizados fora do horário de trabalho, flexibilidade no horário de trabalho, venda de produtos ou serviços da empresa ao preço de custo, dentre outros.

Dado o alto custo em oferecer todos esses benefícios, algumas empresas oferecem a possibilidade dos funcionários escolherem algumas vantagens, permitindo adaptar os benefícios, dentro de limites, às prioridades e desejos de cada um.

Existem também benefícios específicos concedidos para dirigentes de alto nível como a participação nos resultados, premiação por desempenho e opções de compra de ações.

Sabe-se da importância que as empresas alinhem seus incentivos aos seus objetivos e estratégias, já que eles podem influenciar muito no comportamento dos funcionários. E para elaboração de um plano de remuneração é crucial que a empresa identifique o que se deseja obter a partir dele e como ele se alinhará com os objetivos da organização. Portanto, é fundamental que o sistema de remuneração e seus incentivos da empresa estejam alinhados com suas estratégias.

O motivo das empresas investirem em treinamento é o de proporcionar a seus funcionários novas habilidades e capacitações, aprimorar as que eles já possuem, para que estes possam produzir mais e com mais qualidade, trazendo o retorno deste investimento.

Outros fatores são importantes tais, como: capacitar os empregados no que tange as particularidades e especificidades do negócio da empresa; novas funções e processos que surgem decorrentes do avanço da tecnologia; entre outros. Independente do motivo, o 
investimento em treinamento é fundamental, pois, sinaliza a importância que a empresa dá a seu pessoal, o que pode servir como um bom motivo para atrair e reter bons profissionais.

Uma técnica bastante utilizada nas grandes empresas é a job rotation, ou seja, rotação de funções que tem o intuito de treinar o pessoal para assumir novas posições. A principal vantagem deste treinamento é proporcionar uma visão holística da empresa para seus funcionários, entretanto, deve ser bem planejado para que as pessoas não fiquem muito pouco tempo em cada função, e não tenham capacidade de assimilar todo conhecimento necessário, o que prejudicaria seu desempenho futuro. Em algumas empresas de grande porte, também são desenvolvidos programas de orientação por meio de mentores que são administradores de alto nível com muita experiência e tempo de empresa, e que orientam jovens em potencial. O grande objetivo destes mentores é assegurar que estes jovens tenham condições de se desenvolver e atingir posições maiores a médio/longo prazo.

As técnicas mais simples, mas que também desenvolvem pessoas com muita eficácia são os treinamentos por meio de substituições temporárias, no caso de ausência do chefe por motivo de saúde ou viagem a trabalho, por exemplo. Além disso, há também o treinamento por meio das incumbências especiais como acompanhamento de pessoas mais experientes em viagens de negociação, acompanhamento de projetos, ou quaisquer outras atividades que sirvam como fonte de aprendizado como cursos, palestras e seminários.

Muitas empresas criam em seus sites canais de treinamento não só para seus funcionários, mas também fornecedores e clientes. A possibilidade de treinar sem a necessidade da presença física não só diminui o custo da empresa, mas também aumenta a satisfação de muitos funcionários pelo fato destes terem mais flexibilidade em escolher o melhor horário do dia para realizar seu treinamento.

Existem os treinamentos específicos a cada público-alvo como a integração aos novos empregados que consistem em informá-los sobre a empresa e seus objetivos, políticas, produtos, normas, horário de trabalho e todas as informações que a empresa julgar necessário para inserção do novo membro.

Tem-se que a descrição de cargo é feita de uma forma mais genérica que envolva várias funções, por exemplo: um funcionário responsável pelos registros e anotações em carteira e o outro controlando as férias e rescisões do pessoal, duas funções distintas, porém ambos estão sob o mesmo cargo de "assistente pessoal". 
Uma descrição de cargos e funções é importante para uma administração por metas, na qual o funcionário tem bem delimitado suas obrigações e em cima de que este será cobrado; bem como para o sistema de remuneração funcional, que se baseia nos cargos e no trabalho desenvolvido.

Antigamente, as empresas eram responsáveis pelo plano de carreira de seu pessoal. Hoje em dia, muitas empresas responsabilizam seus próprios funcionários para tal, já que atualmente "[...] a criatividade, motivação e envolvimento (a partir de uma grande identidade entre indivíduo e empresa) são peças chaves para produzir de acordo com as necessidades organizacionais" (ARAUJO; GARCIA, 2009; LACOMBE, 2005).

A identidade dos funcionários com a empresa é um ponto crucial, pois atinge diretamente a motivação e o desempenho do funcionário. É preciso que este se identifique com a missão da organização, seus valores, modo de agir com a sociedade, dentre tantos outros fatores, para que seu trabalho faça sentido e possa realizá-lo com prazer.

Os grandes objetivos do plano de carreira são facilitar a exposição das oportunidades que a organização oferece; o auxiliar no desenvolvimento, já que os funcionários vão se motivar a atender as expectativas da empresa; e auxiliar, tanto a empresa, quanto ao funcionário, sobre os próximos passos que podem ser dados. Dentre as principais vantagens desta ferramenta é a própria retenção de talentos, já que a empresa mostra suas perspectivas para cada indivíduo e estes se motivam a continuar e trabalhar mais por isso; movimentação eficaz de pessoas, ou seja, remanejamento de pessoas capacitadas; e identificação do perfil necessário para empresa.

Para estabelecer um planejamento de carreiras, entretanto, a empresa precisa estruturar suas políticas internas em prol disto, ter recursos para gerir todos os orientandos e ter um sistema de administração de carreiras estruturado, que possa fazer valer toda a orientação e não ficar apenas na teoria.

Segundo Araujo e Garcia, a saúde de trabalho visa "[...] prever acidentes, analisando suas ocorrências e trabalhando no sentido da redução ou eliminação das doenças ocupacionais e dos riscos acidentais" (ARAUJO; GARCIA, 2009; LACOMBE, 2005). Busca também manter a integridade física e mental dos trabalhadores para que estes exerçam suas funções em condições adequadas que propiciem o seu desenvolvimento.

As empresas devem estar atentas para oferecer essas condições ambientais adequadas, as quais se incluem todas as variáveis pelas quais as pessoas estão submetidas no dia-a-dia, 
tais como: luz, temperatura e ruídos, por exemplo. Deve-se haver o controle também dos fatores causadores de doenças, que são específicos a cada tipo de negócio. Além disso, a empresa deve fornecer programas constantes para educar os funcionários sobre a utilização correta das atividades a fim de prevenir, reduzir e até mesmo eliminar todas as causas que podem ser prejudiciais à saúde.

A segurança do trabalho preocupa-se em garantir um ambiente seguro para que o trabalho seja executado. Para isso é necessário identificar as principais causas de ocorrências de acidente de trabalho; corrigi-las, se necessário, e fazer uma manutenção regularmente das estruturas físicas; e realizar treinamentos a fim de prevenir futuros acidentes.

A saúde no trabalho pode ser exercida em três áreas: medicina preventiva, prevenção sanitária e medicina ocupacional (ARAUJO; GARCIA, 2009; LACOMBE, 2005).

A medicina preventiva visa prevenir e controlar doenças que possam, por ventura, impossibilitar os trabalhadores de cumprirem suas atividades. Para isso, é demandado um acompanhamento por meio de exames regulares que auxiliam na prevenção de doenças, e também, medidas profiláticas e demais procedimentos, se necessário.

A prevenção sanitária tem como objetivo uma vigilância perante o ambiente de trabalho para que este esteja sempre em condições adequadas. Um exemplo disso seria a vigilância sobre o estoque de alimentos na cozinha.

A medicina ocupacional tem como objetivo adaptar as pessoas da organização às suas funções prevenindo contra riscos à sua saúde. Para tal é necessário a realização de exames médicos, bem como a estruturação de programas de reabilitação e readaptação.

Estas três áreas completam o ciclo de atividades de saúde do trabalho. Deve-se ressaltar que as companhias não devem acompanhar e manter a qualidade no ambiente de trabalho, visando apenas conforto, mas buscando, principalmente, uma maior eficiência e eficácia no processo produtivo, gerando melhores resultados para empresa, bem como melhores condições para seus funcionários.

Entretanto, sabe-se que para manter um sistema de segurança eficiente há um alto custo envolvido tanto pela implantação em si, que exige uma grande mobilidade de recursos, quanto para manutenção do sistema, e um alto controle e comprometimento de todos os funcionários.

O clima organizacional (SANTOS, 1999) reflete o grau de satisfação dos funcionários perante seu ambiente de trabalho. Estão fortemente vinculados à motivação dos mesmos, seus 
interesses, motivação com a empresa, relacionamentos interpessoais, facilidade de comunicação interna, colaboração entre as pessoas, dentre outras variáveis (LACOMBE, 2005).

Um administrador sabe da necessidade em manter um bom clima organizacional para que seus funcionários trabalhem motivados, sentindo-se parte da empresa, se identificando com seus valores e missão, para que eles possam ter desempenhos melhores e seja criado um clima mais amigável e favorável para a execução das tarefas. Em empresas onde o clima organizacional é bom, as pessoas tendem a ser mais proativas, compartilhar conhecimentos, confiar nos chefes e colegas de trabalho, e "vestem a camisa" da empresa, possuem um grande sentimento de pertencimento. Esse ambiente potencializa as capacidades individuais e facilita para obtenção de melhores resultados. Entretanto, em ambientes onde o clima organizacional é ruim, o funcionário geralmente faz o mínimo para se manter no emprego, e o número de faltas e rotatividade é muito maior.

Para mensurar o clima organizacional podem ser feitas pesquisas e avalições que identifiquem a satisfação das pessoas perante a empresa e a partir daí identificar as principais causas. Tendo mapeado as causas, os gestores podem criar estratégias para reverter a situação e melhorar o ambiente.

A importância do fundador da empresa para a criação da cultura organizacional, sobretudo no cenário de pequenas e médias, o torna capaz de criá-la e moldá-la desde a sua concepção. Segundo Macedo (2001), a figura do fundador nas organizações familiares tende a apresentar aspectos peculiares, tais como: supervalorização de relações afetivas em detrimento de vínculos organizacionais; valorização da antiguidade, considerada como um atributo que supera a exigência de eficácia ou competência; exigência de dedicação, postura de austeridade e expectativa de alta fidelidade em relação à organização; supervalorização de aspectos emocionais quando decisões têm de ser tomadas; o autoritarismo e o paternalismo nas relações das chefias com seus subordinados; preferência pela comunicação verbal e pelos contatos pessoais; posturas centralizadoras, autoritárias e, muitas vezes, paternalistas nos dirigentes em relação a seus subordinados; o processo decisório tende a ser centralizado, residindo no chefe à última instância para a tomada de decisões e tende para um padrão mais espontâneo, improvisado e por impulso; provisão de cargos, as promoções e premiações geralmente observam critérios de confiança, lealdade e antiguidade dos trabalhadores, em detrimento de sua produtividade e/ou qualidade do serviço prestado. 


\section{METODOLOGIA}

Este é um estudo de caso exploratório com caráter de análise em profundidade. Segundo Yin (1994) uma das utilidades de tal método é estudar determinado assunto em seu ambiente natural, de aprender e gerar teorias (ou aprimorar as já existentes) a partir da prática. Dessa forma, tornando-se o método mais adequado para a pesquisa visto o objetivo principal do estudo. Além disso, a disponibilidade e o interesse do gestor em fornecer informações foram cruciais para a escolha da metodologia, bem como a realização da pesquisa em si.

Para tal, dividiu-se o estudo de caso em duas partes. A primeira delas refere-se a uma pesquisa qualitativa com o gestor/proprietário da empresa, de modo a identificar as três vertentes estudadas no referencial teórico, processos de gestão de pessoas, a estratégia de pessoas e o clima organizacional. Este método foi selecionado, pois, além de buscar identificar quais procedimentos são executados pela empresa e a adequação dos mesmos diante a teoria estudada, também foi avaliada a postura do gestor perante os principais instrumentos da área, bem como questões de estratégia e clima organizacional. Buscou-se avaliar a percepção deste diante de tais tópicos e como que sua postura interfere no seu modo de gestão.

A entrevista foi de modo semiestruturado para permitir uma maior flexibilidade $\mathrm{e}$ aprofundamento em determinados assuntos de acordo com as respostas do gestor/proprietário.

Foram feitas imersões no dia-a-dia da empresa, acompanhando suas atividades durante alguns dias, de modo a identificar possíveis pontos que poderão não ser evidenciados na pesquisa realizada e no discurso do gestor, visando uma maior contribuição ao trabalho a partir de uma percepção neutra e sem vieses.

Foi aplicado junto aos 23 funcionários da empresa, de 38 funcionários - representando, portanto, aproximadamente $61 \%$ - sendo uma amostra significativa, o questionário utilizado na pesquisa realizada para mensuração do clima organizacional foi montado segundo os moldes encontrados na literatura e testado junto a um pequeno grupo de funcionários de outra empresa.

Como dados secundários foram utilizados documentações disponíveis da empresa, principalmente no que tange a tais processos, recrutamento e seleção, treinamentos, manual de qualidade existente, entre outros. 


\section{CONTEXTUALIZAÇÃO}

A Panther Embalagens Ltda. é uma cartonagem, ou seja, adquire placas de papelão ondulado de fornecedores para produzir caixas e acessórios do material em questão. De origem familiar, a empresa foi fundada em 1988, em Guarulhos, pelos irmãos Paulo Eduardo Antunes Ventura e por Flávio Marcelo Antunes Ventura. Inicialmente, foi construída em uma área de $600 \mathrm{~m}^{2}$ no bairro da Vila Galvão, em Guarulhos, e possuía apenas 13 funcionários. Em 1995, a empresa foi transferida para Bonsucesso após a aquisição de um terreno, ainda na mesma cidade, o que permitiu a expansão de suas operações. Após novas aquisições de terrenos no local, a empresa ampliou ainda mais seu negócio, tendo atualmente uma área própria de $4.500 \mathrm{~m}^{2}$ sendo $3.600 \mathrm{~m}^{2}$ de área construída e conta com a participação de 38 funcionários.

Esta ampliação das instalações foi acompanhada também de um maior investimento em maquinário de modo a adaptar-se à demanda de seus clientes, a melhoria da produtividade e qualidade dos produtos. Além disso, houve um melhor aproveitamento do espaço em prol do benefício dos funcionários por meio da construção de salas de treinamentos para os mesmos, e espaços de lazer e confraternizações.

Quanto à gerência da empresa, esta era dividida entre os dois sócios - sendo Paulo Ventura o responsável pela parte administrativo-financeira e Marcelo Ventura, produção e dos assuntos relacionados à fábrica. Por motivos maiores, em 2011 houve a cisão da sociedade, sendo Paulo o atual gestor da Panther Embalagens Ltda., e o responsável final por todas as operações.

Ressalta-se que esta cisão trouxe grandes impactos na gestão da empresa como um todo uma vez que o atual gestor ficou muito mais sobrecarregado e, como se observa ao longo do trabalho, impacta significativamente na gestão de pessoas da empresa.

Visando atender às necessidades do mercado de embalagens, a Panther Embalagens Ltda. oferece soluções para as necessidades desde caixas de papelão ondulado (como caixa normal, corte e vinco, telescópicas, por exemplo), bem como acessórios para acomodação e proteção de produtos dentro das embalagens (separador, tabuleiro, divisórias, calços, entre outros).

Pouca importância foi dada à parte de gestão de pessoas e à formação de uma área devidamente estruturada. Tal fato se comprova pela existência de apenas uma pessoa responsável por tal departamento no período de 2003 a 2004, época na qual houve 
investimentos em prol dos funcionários, seja por meio de treinamentos, bem como pesquisas de clima organizacional. Fora desse período, assuntos relacionados à parte de Departamento Pessoal, como admissões, demissões, manual da qualidade, e assim por diante, eram e realizam-se pela gerente administrativa. Pelo fato desta possuir diversas atividades e responsabilidades, no que tange às atividades mais operacionais e burocráticas da área, tais procedimentos são por ela realizados. Aspectos que exigem um maior investimento e análise como percepção de treinamentos necessários, a preocupação com a satisfação dos funcionários, por exemplo, não são contemplados pela gestão atual por falta de tempo da responsável, mas percebidos e entendidos pelo gestor/proprietário. Ressalta-se o interesse do gestor em investir em tal área, dada a construção de uma sala de treinamentos quando houve a expansão da empresa.

Em conversas preliminares com o proprietário/gestor, Paulo Eduardo Antunes Ventura, identifica-se as falhas no que tange a gestão de pessoas da empresa, como também suas contribuições positivas para o tema.

\section{ANÁLISES}

Sobre a análise, a mesma será dividida em quatro partes: pesquisa realizada com o gestor/proprietário, onde serão redigidas as percepções deste em relação aos temas abordados; análise quantitativa, realizada por meio da pesquisa de clima organizacional; percepções dos entrevistadores acerca de características do gestor e ambiente de trabalho por meio de vivência de alguns dias na empresa; análise geral, que visa combinar todos os fatores observados e discutidos nos tópicos anteriores bem como suas relações com a teoria.

O gestor/proprietário afirmou que não havia um planejamento específico. Por ser uma empresa de pequeno porte, a rotina era muito dinâmica, onde se prioriza a solução de problemas corriqueiros, não havendo tempo suficiente para dedicação às atividades de gestão de pessoas de fato, tão pouco planejamento da empresa a médio e longo prazo. O que está de acordo com o encontrado na literatura.

A empresa não possui um critério para definição de investimentos. Os investimentos são realizados na medida em que as necessidades aparecem, entretanto, no que diz respeito à infraestrutura e maquinário, o gestor/proprietário discorreu que todo investimento necessário já foi realizado. Constatou-se uma preocupação com os insumos tangíveis. Os investimentos que faltam na empresa são nas áreas de tecnologia de informação, melhoria de processos, 
métodos para adquirir informações mais apuradas, melhor controle financeiro (principalmente em relação ao custo dos produtos e margem de contribuição dos mesmos) e treinamento do pessoal. Nota-se que a maioria das necessidades não atendidas são intangíveis.

O principal ponto forte da Panther é a sua solidez. Por já estar atuando no segmento há 25 anos, possui um nome sedimentado e uma grande credibilidade no setor. Sobre os pontos fracos, o proprietário cita a "falta de profissionalismo e gestão amadora", sendo uma característica muito recorrente de empresas deste porte.

Quanto às ameaças, destacou-se que a empresa saiu, operacionalmente, do nível de pequena empresa, entretanto não o suficiente para se equiparar às grandes empresas. Embora ainda seja considerada uma pequena empresa, pelos critérios de faturamento e quantidade de funcionários, esta já possui estrutura que lhe permite atingir um estágio maior. Isto é uma ameaça na medida em que as micro empresas do seguimento de cartonagem, por não terem uma estrutura de custo, acabam colocando seus preços em níveis baixíssimos para conseguir conquistar os pedidos de determinados clientes. A Panther, por já possuir uma estrutura de custo mais estruturada e custos fixos elevados, dado o tamanho da empresa, não consegue competir neste nível. Neste ponto, eles competem com as médias e grandes empresas do setor, já que os preços se assemelham. Entretanto, a Panther ainda não possui um nome e representatividade como grandes empresas do mercado, entre elas Savar, Klabin, e outras. Além de estas possuírem marcas fortes, elas têm capacidade de oferecer um serviço melhor, principalmente no que tange a agilidade, uma vez que algumas delas são totalmente verticalizadas, ou seja, produzem desde as placas de papelão até às caixas, sendo possível um planejamento mais assertivo. Percebe-se, portanto, que a empresa encontra-se em uma situação delicada, pois está sendo pressionada, tanto pelas micro quanto pelas médias e grandes empresas, destacando uma necessidade urgente de um reposicionamento.

Em relação às oportunidades, o reposicionamento no mercado, por ser uma empresa sólida e com nome, acredita-se ser possível por meio de uma estratégia estruturada. O mercado de pequenas quantidades é interessante para ser explorado, exige uma estrutura de custos mais apurada do que a existente atualmente. Existe a possibilidade de produção de outros insumos para agregar valor ao serviço, entre outras possibilidades com o planejamento tributário, buscando-se uma maior economia dentro da legalidade.

O sistema de recrutamento utilizado pela empresa é o externo. Utilizam três agências especializadas, que ficam responsáveis por encontrar o perfil de profissional desejado e 
agendar a entrevista com o gestor. Como, majoritariamente, os cargos requeridos são operários para fábrica, o gestor afirma que poucos são os requisitos exigidos. Os pontos mais analisados no processo de recrutamento são o cargo, a experiência profissional anterior e a pretensão salarial. Caso o entrevistado seja aprovado, ele é submetido a um período de 60 dias de experiência e, tendo desempenhado um bom serviço no período, é contratado efetivamente pela empresa.

Quanto ao recrutamento interno, o mesmo é feito de uma forma incorreta. O processo se dá à base de tentativas, colocando um funcionário em uma máquina, e observando a sua adaptabilidade e seu desempenho para tal cargo. Faltam meios de profissionalizar e mensurar o desempenho dos funcionários para contratar ou até mesmo promovê-los, o que demonstra a falta de critérios formais para tal procedimento. Sobre este tópico, há reconhecimento do gestor quanto a esta falha.

Não existe um plano de remuneração específico na empresa. Os salários são baseados no mercado por meio de contato com concorrentes e sindicato. Por haver muitos concorrentes nas redondezas, o estabelecimento/relacionamento de amizade com a maioria deles permite essa troca de informações quanto a salários e benefícios praticados.

Não há uma grande rotatividade de funcionários entre as empresas do mesmo seguimento, no entanto, quando isto ocorre, geralmente é por questão de oportunidades que vão além da questão salarial, já que os salários e benefícios são praticamente os mesmos.

Os benefícios concedidos são assistência médica, assistência odontológica, participação nos lucros e resultados e alimentação, além dos encargos sociais previstos por lei. Tais benefícios são fixos, ou seja, os funcionários não possuem direito de escolha como no "Plano Cafeteria", entretanto, há o direito de renunciar, como por exemplo, a contribuição sindical, que é opcional, podendo o funcionário se associar ou não.

Tais benefícios são comunicados para todos os funcionários no momento da contratação. Estes benefícios já são oferecidos há muitos anos e não houve corte de nenhum benefício na empresa. No momento, enfrenta-se um grande problema, pois o custo do plano de saúde pago a seus funcionários dobrou. O proprietário afirmou que certamente não cortará tal benefício, mas que terá que pensar em outras soluções e buscar alternativas, já que os funcionários não vão querer pagar mais caro pelo mesmo serviço.

Em relação à importância dos benefícios e seu papel estratégico, o gestor citou: "Benefícios são tão importantes quanto salário. O que adianta ter um salário bom e não dar 
nada para o funcionário? Faz parte do pacote." Em uma escala de zero a dez, ele deu nota nove para representar a importância dos mesmos, demonstrando uma boa percepção de técnicas de gestão e sua importância para os funcionários.

Ultimamente a empresa não tem realizado nenhum treinamento, mas costumava fazer quando tinha uma funcionária responsável pelo departamento de recursos humanos, no período de 2003 a 2004.

Durante este período, foram realizados treinamento de $5 \mathrm{~S}$, programa que tem como objetivo a qualidade total do processo por meio da organização e disciplina no ambiente de trabalho. Além deste, também fizeram alguns treinamentos de Kaizen, que visa à melhoria contínua por meio de pequenas mudanças de baixo custo. Segundo Paulo, um de seus clientes estava implantando este processo em sua fábrica e notaram grandes melhorias e resultados em pouco tempo. Sendo assim, tal cliente passou a oferecer o treinamento a seus fornecedores, também para que estes passassem a implantar essa cultura no seu processo produtivo, visando o aperfeiçoamento contínuo. Porém, este método só foi executado três vezes na empresa. Além destes treinamentos, alguns funcionários já realizaram cursos de impressão no SENAI.

Segundo o gestor "Tem muita coisa para fazer. Mas tem que ter uma pessoa para ficar movimentando isto. Na correria do dia-a-dia eu não consigo nem pensar nisso". O gestor ainda comentou que gostaria de promover mais treinamentos, tanto técnicos (de impressão, sobre o próprio papelão, entre outros), quanto motivacional.

Quanto ao treinamento recebido pelos funcionários para executarem suas tarefas cotidianas, este é realizado de maneira informal, por meio de instruções dos líderes de cada setor e baseado em observação dos demais funcionários. Não há um treinamento específico que propicie um bom desempenho de suas atividades.

Segundo o gestor, a realidade da empresa não permite que ela tenha um plano de carreira atualmente. Por ter uma estrutura de pequeno porte, muito dinâmica e com processos amadores, pouco estruturados, esse tipo de planejamento nunca foi feito.

Citou também que há a descrição de todos os cargos, por conta da ISO 9000, mas os funcionários não tem conhecimento de tal documento, nem mesmo quando são contratados. Evidenciando que tais documentos são muito mais por conta de exigências para manter o padrão de qualidade do que para serem efetivos, de fato.

A segurança na fábrica é realizada por uma empresa terceirizada, que auxilia a Panther em tal aspecto. Entretanto, não há uma fiscalização se os procedimentos estão sendo seguidos. 
O gestor citou que diversas vezes, andando na fábrica, viu procedimentos sendo feitos de forma errada e ele mesmo teve que advertir os funcionários. A princípio, tal responsabilidade seria do Supervisor da fábrica, porém, como este também realiza diversos trabalhos, não consegue acompanhar de perto e fiscalizar a rotina dos 32 operários da produção.

Não se constata a realização de treinamentos de normas de execução das tarefas para os funcionários ingressantes. Há apenas o fornecimento dos equipamentos de segurança, que são trocados periodicamente. Quanto às formas de execução de trabalho, estas se aprendem por meio do contato com o líder do setor, instruções do mesmo e observações diárias.

O gestor/proprietário cita que atualmente esta é uma das principais fontes de preocupação, a segurança de seus funcionários. Citou também que até hoje só houve três acidentes de trabalho durante os 25 anos de existência e que a empresa possui o certificado da ISO 9000 desde 2000. Porém, ele enxerga a necessidade urgente de melhorias neste aspecto.

$\mathrm{Na}$ Panther, segundo o gestor/proprietário Paulo, foram realizadas pesquisas de clima organizacional há muitos anos atrás. Ele não soube especificar a última vez em que fizeram e nem tem arquivado os resultados, porém considera um ponto muito importante para gestão da empresa. Segundo ele “(...) é o que mantém a equipe motivada. É o que mantém a empresa para frente".

A percepção do proprietário em relação aos métodos que podem ajudar a melhorar o clima organizacional: "Acho que o clima pode ser melhorado por meio dessas ferramentas de treinamento, motivação, pesquisa de clima, saber o que o funcionário quer, aonde quer chegar, entender um pouco mais sobre ele. Senão, o cara está aí e não sabe nem porque está, e nem eu sei o que posso esperar dele".

A fim de entender a percepção do gestor em relação a sua empresa e depois comparar com a pesquisa quantitativa, foi perguntado qual seria, na opinião dele, em uma escala de zero a dez, a nota que ele considera estar o clima organizacional de sua empresa, e a resposta foi seis e meio.

Foram respondidos 23 questionários, de 38 funcionários da empresa, o que representa, aproximadamente, $61 \%$, sendo uma amostra significativa e que valida a pesquisa realizada. A partir da compilação dos dados e da elaboração da tabela de respostas, foram identificados alguns problemas principais, sendo estes: autonomia, comunicação e relacionamento entre os funcionários. 
A partir da pesquisa de clima, pode-se perceber que os funcionários sentem que não detém de autonomia para tomarem decisões, apesar de em geral se considerarem satisfeitos quanto ao cargo, à realização profissional e à remuneração. Quanto à qualidade da empresa e do trabalho, sentem que estão adequados, porém, as orientações que recebem não são percebidas como claras e objetivas e isso é destacado em relação à comunicação com a diretoria que é vista como pouco aberta às ideias e críticas dos funcionários, além de não se sentirem muito valorizados.

Por outro lado, os funcionários se sentem respeitados pela chefia de modo geral e do modo como o relacionamento interpessoal se dá dentro da empresa, o qual poderia ser apenas um pouco mais baseado na cooperação entre os departamentos e no trabalho em equipe.

Fatores identificados que podem merecer atenção são: sensação de instabilidade no emprego, a falta de investimentos em treinamento e desenvolvimento, conforme pontuado anteriormente e a necessidade de melhora nas características relacionadas às condições de trabalho de ventilação e organização do espaço.

Vale ressaltar por fim, que a visão geral dos trabalhadores é que a empresa é considerada um bom lugar para trabalhar e também que o gestor dá bons exemplos a seus funcionários. Este resultado mostra a boa imagem da empresa e de seu proprietário/gestor, perante seus colaboradores.

Dessa forma, pode-se perceber que o gestor/proprietário subestimou o clima organizacional da empresa, dando nota 6,5 , quando, por meio da pesquisa de clima e da tabulação, a nota perante a percepção dos funcionários é 7,76.

O primeiro ponto a ser considerado é em relação à cultura organizacional. Foi observado que há uma cultura de pouca eficiência em resolução dos problemas. Todos os imprevistos e dificuldades que surgem, seja na produção, ou na área administrativa, são comunicados ao gestor e este é o responsável por resolver. Desde problemas mais sérios em relação a atrasos de entregas, a casos mais simples e secundários, como desentendimento entre funcionários. Foi observado que os funcionários apenas comunicam as falhas e os problemas que devem ser resolvidos, raramente propondo alguma solução, ficando tudo a cargo do gestor/proprietário.

As principais decisões são tomadas pelo gestor/proprietário, por exemplo: decide se vai comprar matéria prima, de qual fornecedor, qual a quantidade e a qualidade. Ele delega apenas a questão operacional de efetuar a compra, o que evidencia, portanto, a centralização 
de decisões e a sobrecarga do gestor, sendo um contraponto em relação à sua entrevista na qual ele afirma que delega a maioria das tarefas.

De qualquer maneira, esta cultura é um ponto crucial, por limitar muito as funções de Paulo como gestor da empresa, que deveria ter um papel mais estratégico, restringindo-se apenas à resolução de problemas.

Outro aspecto importante observado são as reuniões pouco produtivas. Normalmente são reuniões longas, na qual o foco está em tentar identificar o erro e quem foi o responsável, ao invés de focar na solução. Além disso, as reuniões, de modo geral, acabam sem a definição de próximos passos, responsáveis e prazos, e sem uma formalização do que foi discutido, abrindo mais espaço para que novos erros ocorram, já que se espera um entendimento igual sobre o que foi discutido entre todas as partes - o que nem sempre ocorre.

O principal motivo de problemas e necessidade de reuniões é a falha no fluxo de informação. Por uma falta de estruturação organizada dos processos, bem como a falta de clareza nas responsabilidades e funções.

Como pôde ser observado por meio das pesquisas e das observações em campo no diaa-dia da empresa, o gestor possui um alto conhecimento da sua empresa, além de uma boa noção de gestão e importância dos principais pontos destacados na teoria, como segurança no trabalho, remuneração e benefícios, pesquisa de clima organizacional, entre outros.

Entretanto, devido a um crescimento desestruturado da empresa, a saída de um dos sócios, perfil do gestor atual, e uma exacerbada centralização, o gestor fica extremamente sobrecarregado para resolver questões operacionais, muitas vezes simples, e acaba não exercendo seu papel estratégico como gestor.

Partindo de uma análise mais macro do diagnóstico interno da Panther Embalagens Ltda., no que tange à gestão de pessoas, pode-se afirmar que esta é afetada por três causas principais: gestão de processos; falhas na estratégia e centralização das decisões.

Um dos problemas mais corriqueiros é em relação ao fluxo de informações. Tal falha se dá justamente por uma definição de processos amadora e pela falta de conhecimento, por parte dos funcionários, de quais são suas funções e responsabilidades, citado, inclusive, na entrevista com o gestor. Pelo fato de tais erros acontecerem diariamente, há um desgaste muito grande no relacionamento entre o gestor e os funcionários e entre os próprios funcionários na fábrica, principalmente, como observado na pesquisa de clima organizacional. 
Isso se deve muito ao depoimento do próprio gestor/proprietário a respeito dos líderes de setor: "Eles estão líderes, e não são líderes" evidenciando a questão destes não exercerem uma liderança, de fato. Além de não terem características de líderes, não atuam como um time propriamente dito, entre os setores. O gestor tem contato e cobra todos os funcionários, sendo ele líder ou auxiliar de máquina, o que além de sobrecarregá-lo, limita a ação dos funcionários nestas posições já que estes, atualmente, possuem uma autonomia muito pequena. $\mathrm{O}$ mesmo ocorre para o setor administrativo, Paulo tem contato e gerencia todos os funcionários do escritório. A gerente administrativa, além de não ter um bom convívio com as demais funcionárias em que se relaciona diretamente, não exerce seu papel de liderança, tendo uma característica muito centralizadora.

Nota-se que há uma má estruturação das lideranças na empresa, tanto por falta de algumas oportunidades, quanto no papel que tais funcionários estão exercendo, seja por perfil inadequado ou falta de treinamento e melhor instrução dos mesmos.

Por fim, ao analisar o caso em profundidade, pode-se considerar que o estilo de liderança de Paulo Ventura é autocrático e autoritário o qual, como citado na literatura, é recorrente nesse tipo de empresa, fábricas em que são liderados funcionários que operam máquinas na qual o foco é o prazo de entrega do produto final. Outra característica marcante deste perfil de líder é a preocupação excessiva com a tarefa, em si, e a dificuldade em ouvir opiniões alheias.

Faz-se necessário que Paulo exerça uma liderança mais democrática e os envolva mais, por meio da criação de um espírito de time, para uma cooperação maior entre os diversos setores e um melhor convívio entre os funcionários. Pelo fato ser uma figura muito respeitada na empresa, é importante que este papel aglutinador seja realizado pelo gestor.

Pode-se destacar algumas características do gestor que apresentaram falhas e são cruciais para exercer uma boa liderança, a saber: clareza na comunicação, para saber expor aos seus liderados, aonde quer chegar; maior abertura para ouvir opiniões alheias, sem que seja levado para o lado pessoal; e, saber reconhecer seus funcionários.

A descentralização é necessária, não apenas por ser desejada uma maior autonomia por parte dos colaboradores, mas por ser crucial para que a gestor possa ficar responsável por questões mais estratégicas e para que a empresa consiga caminhar rumo a seu crescimento e não fique estagnada por problemas operacionais e estruturais como os existentes atualmente. 
É importante destacar também que é necessário um maior investimento de tal área no plano interno. Para tal, é necessária a elaboração de métodos que avaliem o funcionário por seu desempenho, baseado em métricas e fatores plausíveis, para que a avaliação possa ser feita de forma justa e não apenas na percepção ou em tentativas, como é realizado atualmente. O recrutamento no plano interno é muito vantajoso, pois, além de exigir um baixo investimento, é um processo mais ágil e garante uma maior confiabilidade na medida em que o funcionário já está adaptado à realidade da empresa, além disto, irá aumentar a satisfação dos funcionários já que, como observado na pesquisa de clima organizacional, estes têm demandado um maior reconhecimento e esperam construir uma carreira na empresa. Havendo esse recrutamento interno e promoções dos funcionários atuais, a gerência demonstrará que a empresa se preocupa com seus funcionários e valoriza-os. Isto, além de aumentar a satisfação, é uma forma de fidelizá-los, fator muito importante já que, segundo a entrevista do gestor, há dificuldade na contratação deste tipo de mão de obra, a baixos custos, atualmente.

$\mathrm{O}$ treinamento e desenvolvimento analisado na entrevista realizada têm falhas e carece de investimentos. Para suportar a descentralização proposta é crucial que os funcionários estejam preparados para assumirem mais responsabilidades. Os treinamentos prioritários são os de capacitação nas funções de segurança do trabalho, para mitigar os erros que ocorrem atualmente e evitar danos maiores. Além disso, é importante, também, um treinamento que vise um maior alinhamento com a empresa, a fim de disseminar a cultura desta, bem como suas práticas de qualidade. Posteriormente, é importante que sejam realizados treinamentos técnicos, que aumentem o aprimoramento profissional dos funcionários, bem como motivacionais.

A falta de definição de cargos e funções foi identificada como um dos principais causadores dos problemas. É necessário que tais descrições não fiquem apenas no manual, mas que sejam aplicadas na prática, fazendo com que os funcionários tenham conhecimento de quais são suas atividades, suas responsabilidades e tenham um parâmetro para saber como eles serão cobrados e avaliados.

Pode-se dizer que, após a descentralização de atividades e decisões, como analisado, bem como a estruturação dos processos de gestão de pessoas, o proprietário estará apto e terá disponibilidade para exercer seu papel de forma mais estratégica, explorando melhor as oportunidades indicadas na análise SWOT, elaborando estratégias para mitigar as ameaças apresentadas. 


\section{CONSIDERAÇÕES FINAIS}

Constatou-se a necessidade de uma melhor estruturação da área de gestão de pessoas, tendo um profissional específico para realizar as atividades desta área, para que esta receba a atenção merecida, garantindo que todos os processos sejam cumpridos, tanto por exigências legais quanto para seguir o próprio manual de qualidade da empresa. A atuação desta área mostrou-se extremamente estratégica e revelou que há falta de investimento na mesma, não havendo o estabelecimento de uma estrutura mais adequada que aplique os conceitos de gestão de pessoas vistos nas teorias.

Faz-se necessário a definição de cargos e funções que reflitam melhor as atividades da empresa, de modo a organizar e estruturar adequadamente o fluxo de informações, a fim de evitar as falhas de comunicação existentes. Tais descrições não devem ficar apenas no manual de qualidade, como é feito atualmente, é fundamental que todos os funcionários tenham plena informação de suas responsabilidades e do que é esperado dos mesmos.

A centralização das atividades e tomada de decisões por parte do gestor são características muito comuns às pequenas empresas. A descentralização e maior autonomia dos funcionários deixaram de ser uma questão de opção e passou a ser uma questão de sobrevivência da empresa. Para permitir que esta descentralização ocorra de modo que o desempenho atual não seja prejudicado, é necessária uma reestruturação no quadro de lideranças, desde a escolha de novos líderes para os setores que ainda não o possuem, bem como o treinamento e capacitação dos líderes atuais para que eles possam adquirir maior conhecimento e confiança, para estarem preparados a assumir responsabilidades maiores e liderarem, de fato, seus times. Por meio deste empoderamento dos líderes, o gestor poderá se focar em questões mais estratégicas para gestão de seu negócio.

Como constatado no perfil do gestor, se faz necessário que este utilize uma liderança mais democrática, envolvendo mais os funcionários, de modo a criar um sentimento de time na empresa. Como observado na pesquisa de clima organizacional, este é muito respeitado e admirado pelos colaboradores, o que reforça a importância do seu papel muito mais atuando como um líder, de fato, do que apenas como um administrador.

$\mathrm{O}$ treinamento dos funcionários quanto à segurança no trabalho não é realizado adequadamente, e é extremamente importante, pois diz respeito à integridade física dos mesmos. Após o treinamento dos líderes por setor, pode-se torna-los responsáveis por analisar 
se seus liderados estão seguindo todas as normas, inclusive de segurança, cabendo aqueles o poder de correção, caso necessário.

Constatou-se que uma pequena empresa pode ter seus processos na área de recursos humanos estruturados e adaptados aos conceitos de gestão de pessoas, mas quando não se tem um responsável pela área, o comprometimento do gestor/proprietário é crucial para o desenvolvimento das pessoas. Observa-se que, embora o gestor/proprietário julgue saber a importância da gestão de pessoas para o negócio, terá dificuldades de conciliar com atividades do dia a dia. $\mathrm{O}$ aspecto cognitivo e a capacidade emocional do gestor/proprietário ajudam na sua atuação neste contexto, mas seu desgaste traz dificuldades para o desenvolvimento das MPEs. O aporte teórico de gestão de pessoas ajudará no enfrentamento das dificuldades.

Observou-se que a Panther Embalagens Ltda. possui uma estrutura que lhe permite crescer e atingir o patamar de uma média empresa. É fundamental que os pontos discutidos ao longo do estudo sejam reparados para que haja uma estruturação sólida da área de gestão de pessoas. $\mathrm{O}$ crescimento de uma $\mathrm{PE}$ está atrelado à satisfação dos funcionários, clientes e qualidade dos serviços prestados, e isto passa pela área de gestão de pessoas.

\section{REFERÊNCIAS}

ARAUJO, L. C. G; GARCIA, A. A. Gestão de Pessoas - Estratégias e Integração Organizacional. $2^{\text {a }}$ ed. São Paulo: Atlas, 2009.

BERGAMINI, C. W. Avaliação de desempenho humano na empresa. 4. ed. São Paulo: Atlas, 1988.

BNDES. BNDES modifica classificação de porte de empresa. Disponível em: <http://www.bndes.gov.br/SiteBNDES/bndes/bndes_pt/Institucional/Sala_de_Imprensa/Notic ias/2010/institucional/20100622_modificacao_porte_empresa.html>. Acesso em: 20 nov. 2013.

BRASIL. Previdência Social. Decreto-Lei n5. 452, de $1^{\circ}$ de maio de 1943. Aprova Consolidação das Leis do Trabalho. Título VI, art. 611 a art. 625. Disponível em: <http://www81.dataprev.gov.br/sislex/paginas/10/1943/5452.htm\#T5>. Acesso em: 27 set. 2013.

BRAVERMAN, H. Trabalho e Capital Monopolista: a degradação do trabalho no século XX, $3^{\text {a }}$ edição. Rio de Janeiro: LTR, 1987.

BURKHARD, D.; MOGGI, J. A Essência da Transformação. RAE-Revista de Administração de Empresas, v. 36, n. 4, out-dez, 1996. 
CORRÊA, Kenneth. Modelo de questionário de pesquisa de clima organizacional para pequenas e médias empresas. Disponível em: $<$ http://www.administracaoegestao.com.br/pesquisa-de-clima-organizacional/modelo-dequestionario-de-pesquisa-de-clima-organizacional-para-pequenas-e-medias-empresas/> . Acesso em 25 set. 2013.

FLEURY, M. T. L. As pessoas na organização. Editora Gente Liv e Edit Ltd, 2002.

HANASHIRO, D. M. M. et al (Org.). Gestão do Fator Humano: Uma Visão Baseada em Stakeholders. $2^{a}$ edição. São Paulo: Saraiva, 2008.

LACOMBE, F. Recursos Humanos: Princípios e Tendências. 1ªedição. São Paulo: Saraiva, 2005.

LEONE, N. M. C. P. G. As especificidades das pequenas e médias empresas. Revista de Administração, São Paulo, v.34, n.2, p. 91-94, Abr./Jun. 1999.

LEONE, N. M. C. P. G. A dimensão física das pequenas e médias empresas: À procura de um critério homogeneizador. São Paulo, Revista de Administração de Empresas, Abr./Jun. 1991.

LIMA, E. As definições de micro, pequena e média empresas brasileiras como base para formulação de políticas públicas. [S.I.]: 2001. Disponível em <http://www.anegepe.org.br/edicoesanteriores/londrina/GPE2001-03.pdf>. Acesso em 19 nov. 2013.

MACEDO, K. B. Empresa Familiar Brasileira: cultura, poder e decisão. Goiânia: Editora Terra. Universidade Católica de Goiás, 2001.

MILKOVICH, George T.; BOUDREAU, John W. Administração de Recursos Humanos. São Paulo: Atlas, 2000.

OLIVEIRA, D. P. R. Planejamento Estratégico: conceitos, metodologia e práticas. 30 edição. São Paulo: Atlas, 2013.

PANTHER. Nossa Empresa. Disponível em: <http://www.panther.com.br/empresa.htm>. Acesso em 25 set. 2013.

PANTHER. Nossos Produtos. Disponível em: < http://www.panther.com.br/produtos.htm>. Acesso em 25 set.2013.

ROBBINS, S.; JUDGE, T.; SOBRAL, F. Comportamento Organizacional. 14ª edição. São Paulo: Pearson, 2011.

SANTOS, N. M. B. F. dos. Clima Organizacional. Pesquisa e Diagnóstico. 1. ed. Lorena: Stiliano, 1999.

SANTOS, N. M. B. F. dos. Cultura organizacional e desempenho: pesquisa, teoria e aplicação. 1.ed. Lorena: Stiliano, 2000. 
SEBRAE-GO. Critérios e conceitos para classificação de empresas. Disponível em: $<$ http://www.sebrae.com.br/uf/goias/indicadores-das-mpe/classificacao-empresarial/criteriose-conceitos-para-classificacao-de-empresas/criterios-e-conceitos-para-classificacao-deempresas>. Acesso em 20 nov. 2013.

ULRICH, D. Recursos humanos estratégicos: novas perspectivas para os profissionais de RH. 3. ed. São Paulo: Futura, 2000.

YIN, R. Case Study Research: Design and Methods. $2^{\mathrm{a}}$ ed. Thousand Oaks, CA: SAGE Publications, 1994. 